\title{
MUSAS EN EL PARAÍSO: \\ apropiaciones del plátano por parte de españoles e indígenas. Nuevo Reino de Granada, siglos XVI y XVII. ${ }^{1}$
}

\author{
MUSAS NO PARAÍSO: \\ apropriações da banana por espanhóis e indígenas. \\ Novo Reino de Granada, séculos XVI e XVII. \\ MUSES IN PARADISE: \\ appropriations of banana by Spaniards and Indians. \\ New Kingdom of Granada, 16th and 17th centuries.
}

\section{Resumen}

La implantación del plátano en el Nuevo Reino de Granada no fue impulsado por la Corona española, como sí sucedió con otros productos alimenticios (p.e. caña de azúcar, gallinas y trigo), sino que se dio de una manera informal, llevado a cabo por algunos europeos desde comienzos del siglo XVI. A pesar de que el cultivo del plátano prosperó muy pronto, tanto que parecía un producto aborigen, la adopción por parte de los indígenas demoró un tiempo; a fines del XVI, solo algunos pueblos lo cultivaban como parte de su tributación, pero no para su consumo. En el XVII, lo adoptan como parte de la dieta, aunque no siempre lo identifican como un alimento vinculado al gusto, sino a la necesidad. Para entender este proceso, es necesario vincular estructuras de consumo, formas de trabajo y demografía. Estos diferentes aspectos de la sociedad permiten ver otras de las facetas de la globalización del mundo, en este caso con un fruto tropical que se impone en otras latitudes tropicales, llevado por los europeos.

Palabras- Clave: Plátano, Historia de la alimentación, Globalización, Consumo, Edad moderna temprana.

\section{Resumo}

A introdução da banana no Novo Reino de Granada não foi impulsionada pela Coroa espanhola, como se sucedeu com outros produtos alimentícios (por exemplo cana-de-açúcar, galinha e trigo), uma vez que se deu de uma maneira espontânea, levado a cabo por alguns europeus desde o início do século XVI. Apesar do cultivo da banana ter prosperado tão prontamente, tanto que parecia um produto nativo, sua adoção por parte dos povos indígenas demorou um tempo; em fins do XVI, somente alguns povos cultivavam a mesma como parte de suas obrigações tributárias, mas não para o seu consumo. No século XVII, eles a adotam como parte

\footnotetext{
${ }^{1}$ Este artículo es producto de la comisión de estudios que la Universidad de Antioquia me concedió para realizar una estancia posdoctoral en Villa I Tatti, The Harvard University Center for Italian Renaissance Studies y forma parte del proyecto (HAR2014-53797-P) "GLOBALIZACIÓN IBERICA: REDES ENTRE ASIA Y EUROPA Y LOS CAMBIOS EN LAS PAUTAS DE CONSUMO EN LATINOAMÉRICA", financiado por el Ministerio de Economía y Competitividad (España).

${ }^{2}$ Profesor titular. Grupo de Investigación en Historia Social. Departamento de Historia. Universidad de Antioquia Colômbia. E-mail: gregorio.saldarriaga@udea.edu.com 


\title{
Musas en el paraíso: \\ Apropriaciones del plátano por parte de españoles e indígenas. Nuevo Reino de \\ granada, siglos XVI y XVII.
}

Gregorio SALDARRIAGA

de sua dieta, ainda que nem sempre a identifiquem como um alimento vinculado ao gosto, porém à necessidade. Para entender este processo é necessário vincular estruturas de consumo, formas de trabalho e demografia. Estes diferentes aspectos da sociedade permitem ver outras faces da globalização do mundo, neste caso com um fruto tropical que se impõe em outras latitudes tropicais levado pelos europeus.

Palavras-Chave: Banana, História da Alimentação, Globalização, Consumo, Idade Moderna.

\begin{abstract}
Banana implantation in the New Kingdom of Granada was not promoted by the Spanish Crown, as was the case with other food products (for example, sugar cane, chickens and wheat), but it has been carried out informally by some Europeans since the beginning of the 16th century. Although banana cultivation prospered very fast, so much so that it looked like an aboriginal product, adoption by indigenous peoples took a while. At the end of the 16th century, only a few cities cultivated it as part of their taxes, but not for consumption. In the 17th century, they adopted it as part of their diet, although they did not always identify it as a food linked to the taste, but to what was necessity. To understand this process, it is necessary to link consumption structures, forms of work and demographics. These different aspects of society allow us to see other faces of the globalization of the world, in this case with a tropical fruit that is imposed in other tropical latitudes, taken by the Europeans.
\end{abstract}

Keywords: Plantain, Food History, Globalization, Consumption, Early modern age.

Como otros productos asiáticos o africanos provenientes de zonas tropicales, el plátano, en sus diversas variantes, se insertó en América con relativa facilidad, especialmente en las zonas cálidas. ${ }^{3} \mathrm{Al}$ igual que el coco, es prácticamente imposible determinar cómo se dieron los primeros pasos de implantación y propagación en América, pero lo cierto es que a muy pocos años del establecimiento de los españoles, ya había noticias con respecto a la abundancia de ambos, razón por la cual parecían aborígenes de las Indias Occidentales. Según Fernández de Oviedo, los dominicos desempeñaron un papel determinante en su difusión, llevándolo de Las Canarias a Santo Domingo. Este proceso de naturalización lo señaló Tomás López Medel a mediados del siglo XVI, al apuntar que: “[...] el plátano, porque, aunque las Indias le heredaron de la Guinea, pero por estar tan recebido y propagado en todas las Indias le podemos llamar el suyo y natural"(LÓPEZ MEDEL, 1990, p.159). Esta naturalización fue tan fuerte, que en el XIX algunos afirmaron que esta musacea era propia del Nuevo Mundo; incluso hoy, el reconocido historiador panameño Alfredo Castillero Calvo ha sostenido la hipotesis que el plátano (Musa Paradisiaca), es decir el que se debe comer cocinado, es originario de América y que el importado por los europeos fue el banano (Musa Sapientum), que se puede comer crudo. Para ello, se basa fundamentalmente en dos grandes argumentos: 1) que en Panamá la documentación de los siglos XVII y XVIII distingue entre una musacea que sería de la tierra y otra que sería foránea. 2) que algunos autores del XVIII y del XIX, especialmente Humboldt, reconocieron como propio de la tierra esta variedad de plátano (CASTILLERO CALVO, 2006, pp. 483-489).

\footnotetext{
${ }^{3}$ Es difícil establecer qué tipo de musácea se trata en cada caso. Por lo tanto, la mayor parte del tiempo se usará el genérico nombre de plátano para designarlas, que es el nombre que se les daba en la documentación.

Revista do Instituto Histórico e Geográfico do Pará (IHGP), (ISSN: 2359-0831 - on line), Belém, v. 07, Dossiê "História da alimentação e do abastecimento na Amazônia", p. 14 - 26, maio / 2020.
} 
Ambos argumentos tienen problemas de fondo para sostener por ellos solos esta idea. Por un lado, el primer argumento solo demuestra que en los términos de Panamá había un tipo de plátano que se daba mejor o en mayor cantidad que otros, que se llevaban desde otras regiones; en modo alguno se puede entender como un reconocimiento de los origenes de domesticación de una planta en especial. De otro lado, utilizar las autoridad de diversos autores del XVIII o del XIX no es una evidencia concluyente, dado que ellos ya estaban viendo el resultado de un largo proceso de aclimatación. Además, con un criterio confuso, Castillero excluye o desconfía de los autores del siglo XVI que apuntaron que el plátano fue llevado por los europeos. Finalmente, para dar más fuerza a su argumento, Castillero sostiene esta idea con lo que él identificó como una lenta adopción del consumo de plátano por parte de los españoles, en contraposición con lo que pasó con el banano.

En este texto, con investigación sobre otra región de la zona intertropical americana, El Nuevo Reino de Granada, asumo una posición contraria a la de Castillero, en tanto entiendo el plátano, en sus diversas variantes, como una planta introducida y propagada por los españoles en el continente americano, dado que así lo indican las fuentes tempranas y que hay ausencia de registros del plátano en hallazgos arqueológicos que den cuenta del periodo previo a la llegada de los europeos a América. Centro la atención en el consumo de españoles e indígenas, con énfasis en estos últimos. A diferencia del estudio Castillero Calvo sobre Panamá, que solo abordó el consumo que se daba en las ciudades, en donde la representación porcentual de los españoles era mayor que en las zonas rurales.

Con este tipo de productos tropicales, es muy fácil asumir su propagación en América como algo ambiental, casi como un hecho inevitable, en el que la mano del ser humano es un mero accesorio; más aun, cuando la documentación no permite rastrear de qué manera se dio esta inserción. Sin embargo, es preciso no perder de vista que buena parte de estos productos comestibles que se propagaron con éxito lo hicieron porque los seres humanos se aprovecharon de ellos y se interesaron en que se reprodujeran lo más pronto posible. Lo interesante en el caso del plátano es que su difusión entre los españoles se dio en suelo americano relativamente rápido, sin que tuvieran una tradición de consumo de musáceas, por lo menos en la península. Asimismo, aunque los grupos aborígenes no tenían ningún producto semejante con el que pudieran establecer una analogía de consumo, se apropiaron de él cuando las condiciones estuvieron dadas. Se trata entonces de esbozar cómo se dio este proceso en los dos grupos, acentuando las diferencias entre ambas apropiaciones, con un ojo puesto en aspectos culturales y otro en aspectos sociales y productivos.

A diferencia de otro tipo de productos que fueron estimulados por la Corona, como el azúcar, que tenían un gran valor comercial, o como el trigo y gallinas, que tenían un componente médico y cultural muy importante para la sociedad hispánica, el plátano fue absolutamente periférico en las consideraciones generales de la Corona y sus oficiales. Su tributación no se impuso como una obligación generalizada a los 
pueblos de tierra caliente. En parte por esta falta de presión de la Corona para que se impusiera su cultivo, tan poca información quedó registrada y, al mismo tiempo, lo que lo hace tan interesante este proceso. Permite observar otra vía de la globalización, en que no hay un interés comercial claro ni un valor social de consumo, y, sin embargo, llegó a ser central en la dieta con el paso del tiempo; en cierto sentido, es lo que se podría denominar vías informales en la mundialización de productos.

Según Fernández de Oviedo, en Santo Domingo — y después en todas las islas donde estaban los españoles asentados y en todas sus "heredades"- crecían los plátanos de manera abundante, "porque son muy provechoso é se gastan quantos hay con la gente, é es muy buena renta para los dueños, porque ninguna costa ponen en los criar(...)"(1944, tomo II, p. 207). Aun con las reservas que se debe mirar esta información, no se puede dejar de observar que se habla de una actividad eminentemente de españoles, que desarrollaban allí donde ellos iban. Esta idea la refuerza el licenciado Juan de Vadillo, oficial real de la Audiencia de Santo Domingo, en carta enviada al rey en 1537 desde Cartagena de Indias. Al hablar de su actividad como gobernador encargado, mientras realizaba el juicio de residencia contra Pedro de Heredia, apuntó que entre sus acciones de gobierno había "fecho plantar de los árboles que acá ay, que son naranxos e limas, plátanos e granadas e árboles de la tierra e ortalizas, que si al principio se obiera fecho, tuvieran aquí que comer e así está una sequedad [...]”. ${ }^{4}$ Su acción no había sido la introducción de los plátanos, sino hacerlos cultivar de manera organizada y en cantidad suficiente para el alimento de la gente en Cartagena. Es importante señalar cuatro cosas con respecto a esta información de Vadillo: por un lado, está justo después de un informe que daba sobre la necesidad de establecer la cría de ganado vacuno en las inmediaciones de Cartagena, por lo tanto ambos aspectos estarían vinculados con el abastecimiento de la ciudad —que tenía cuatro años de fundada - y, en general, de la gobernación. Esto lleva al segundo punto, que está implícito: él estaba haciendo cultivar el plátano porque el gobernador Pedro de Heredia había descuidado sus obligaciones, por estar más preocupado por la búsqueda de oro que por el bienestar de los españoles asentados en su territorio. El tercer punto tiene que ver con el tipo de cosas que señala que sembró: el orden que da es de frutas extranjeras (naranjos, limas, plátanos y granadas), para finalizar con árboles aborígenes y hortalizas. Por lo tanto el plátano se ubica como algo externo, aunque es de los que había en la tierra, previa a la llegada del propio Vadillo. El cuarto es que considera el plátano como fruta, al tiempo que dice que si se hubiera cultivado a tiempo, no faltaría comida. Esto es intrigante, porque en la Edad Moderna no se pensaba

\footnotetext{
4 "Carta del licenciado Xoan de Vadillo a su magestad quenta de su visita a la gobernación de Cartagena. Cartagena, octubre 15 de 1537", en Colección de documentos inéditos, relativos al descubrimiento, conquista y colonización de las posesiones españolas en América y Oceanía sacados en su mayor parte del real Archivo de indias. Madrid: Imprenta Española, 1864-1884, Tomo XLI, p. 414.
} 
que las frutas alimentaran, sino que alteraban la condición del cuerpo; en ocasiones eran más cercanas a la materia médica, que a la alimentación. ${ }^{5}$

De alguna manera se puede pensar que esa posición en la que Vadillo ubica en su descripción el plátano —entre frutas y hortalizas —, correspondería con la misma situación de las musáceas, que tanto se consumían como fruta, como verdura y como pan. Es decir, si bien hay diferencia en el consumo entre la banana y el plátano, más que su naturaleza en sí misma, lo que cambiaba el tipo de consumo era la forma de preparación, así como del contexto de consumo. Para utilizar una idea de Montanari, se podría señalar que contaba con diversas morfologías de consumo, porque podía desempeñar varias funciones dentro de la dieta (MONTANARI, 2006, p. 99) Por ejemplo, en caso de que fueran bananos, evidentemente se podían comer crudas como frutas, y a los europeos les evocaba muchos frutos; por ejemplo, a Carletti le recordaba en el tamaño a "un pepino y con la cáscara lisa, que se monda como la del higo nuestro, pero bastante más gruesa y dura, y lo que está por dentro se come, y es de sabor dulce y al diente como el melón bien maduro pero más seco y sin jugo". ${ }^{6} \mathrm{Si}$ bien se podían comer crudas, como a las musáceas las caracterizaron de naturaleza fría, ${ }^{7}$ en general era aconsejable que se prepararan de alguna manera para corregirlas: ${ }^{8}$ se pasaban al sol, se asaban a las brasas o se horneaban, y luego se les ponía un poco de vino. Estos procedimientos no eran exclusivos de las musáceas, porque se usaban con muchas frutas europeas. Al prepararlas así, los europeos de la época veían la semejanza de la preparación con peras y manzanas. Esta asimilación llegó a tanto que un médico como Juan Méndez Nieto y un cirujano como Pedro López de León, ambos con experiencia en

\footnotetext{
5 "Quantunque i frutti nel reggimento della sanità non convengano per nutrimento, essendo che poco nutriscano, \& generino sangue putrido, \& siano pieni di molta superfluità; nondimeno gl'huomini gli usano per molte altre utilità: dal che si conclude, che non bisogna usarli troppo frequentemente, né in gran quantità, per che quel che si piglia per medicina, \& non per nutrire, bisogna pigliarlo in poca quantità". Castore Durante. Il tesoro della sanità, di Castor Durante da Gualdo, medico, \& Cittàdino Romano. Nel quale s ínsegna il modo di conservar la sanità, \& prolongar la vita, \& si tratta della natura de 'cibi, \& di Rimedi dénocumenti loro. Venetia: Gio Battista Cestaro, 1646, pp. 139-140.

${ }^{6}$ Razonamientos de mi viaje alrededor del mundo (1594-1606). Estudio preliminar, traducción y notas de Francisca Perujo. México: Instituto de Investigaciones Bibliográficas, UNAM, pp. 12 y 13; en la versión italiana se lee "[...] citriolo et da la buccia liscia, che si monda come quella del fico nostrale, ma assai piú grossa e soda, et quello che resta di dentro si mangia, et è di sapore dolce et aspetta al dente, quasi popone ben maturi ma più asciutto et sensa sugo[...]." 6 Francesco Carletti. Ragionamenti del mio viaggio intorno al mondo. Torino: Einaudi, 1989, pp. 33 y 341.

${ }^{7}$ Juan Fragoso. Cirugia universal, ahora nuevamente añadida, con todas las dificultades, y questiones, pertenecientes a las materias de que se trata. Madrid, Viuda de Alonso Martín, 1627; José de Acosta, Historia Natural y moral de las India. Madrid, Casa de Alonso Martín, 1608, Libro cuarto, cap, 21. 249

${ }^{8}$ Para una comprensión de la clasificación de la naturaleza véase Allen J. Grieco. "The Social Politics of pre-Linnean Botanical Classification", I Tatti Studies 4 (1991), pp. 131-149 y "Alimentation et classes sociales à la fin du Moyen Age et à la Renaissance". eds. J.-L. Flandrin and M. Montanari Histoire de l'alimentation. Paris: Fayard, 1996, pp. 479490. Para entender cómo se pensaba que la alimentación afectaba las personas, Rebecca Earle The Body of the Conquistador. Food, Race and the Colonial Experience in Spanish America, 1492-1700, New York, Cambridge University Press, 2012 y Gregorio Saldarriaga "Comer y ser. La alimentación como política de la diferenciación social en la América española, siglos XVI y XVII” Varia Historia, Belo Horizonte, 32.58 (2016), p. 53-77.
} 
Cartagena de Indias, apuntaban que los plátanos eran las manzanas de América, o por lo menos sus sucedáneas en tratamientos dietéticos. ${ }^{9}$

La otra opción era consumirlo en un cocido. ${ }^{10}$ Con este tipo de preparación, ninguno de los que dejó una descripción del plátano estableció una semejanza con una posible contraparte europea, tal vez porque el sabor no permitía hacerlo. Como sea, me atrevo a pensar que cumplía la función de las criadillas de la tierra o de las calabazas, que se ponían en las ollas para acompañar las carnes.

La última forma de consumo era como pan, pero no en el sentido de que se redujera a harina y se amasara en una panificación, sino que el plátano en sí mismo, sin transformación, servía como pan, en ausencia del de trigo o de maíz. Lo interesante es que podía cumplir esta función crudo o asado. Es decir, su paso de fruta a pan no se marcaba por una transformación culinaria, sino por su relación con los otros productos que se estuvieran comiendo, porque en vez de ser un accesorio, se convertía en el centro de la dieta. Para Acosta, que el plátano sirviera de pan era propio de los negros (ACOSTA, 1608, p. 249), pero otros testimonios dan cuenta que era un consumo en el que participaban también europeos, e incluso indígenas (LABAT, 1979). Tal vez la diferencia es que para los negros era un consumo continuado, en tanto que para los europeos e indios era un sustituto, en momentos de necesidad. Esto se puede ver en dos declaraciones de comienzos del siglo XVII; por un lado, el viajero Francesco Carletti señaló que en un penoso viaje de 19 días, hubo "mucha incomodidad de víveres por falta de pan, en vez del cual me tocó comer de aquellos plátanos ya dichos, que cuando están verdes se asan y cuecen bajo las brasas mondándolo antes”(1989, p. 13). De otro lado, los indios de Tomala, en la gobernación de Cartagena, señalaron que "quando les falta el mayz su encomendero no se lo da porque nunca lo tiene y los yndios buscan o comen platanos cozidos crudos y con ellos se sustentan con harto trabaxo y desventura [...]". ${ }^{11}$ Sin duda, el plátano podía ser comida de remplazo por varias razones, pero una de las más importantes es que, por los ritmos de producción del plátano y las condiciones climaticas del Nuevo Reino de Granada, siempre había plátanos disponibles, bien producidos en la misma zona de consumo, o llegaban por medio del comercio. ${ }^{12}$ Además, variedad y versatilidad, que ya se señaló previamente, permitía que estuviera en la dieta de diversas maneras, o como lo dice Acosta: "en algunas partes este es su pan: también hacen vino del. Comese el platano como

\footnotetext{
${ }^{9}$ Dentro de estos procesos de corrección de los plátanos, se les agregaba agua de azahar, canela y azúcar; Juan Méndez Nieto, Discursos medicinales compuestos por el licenciado Juan Mendez Nieto, que tratan de las maravillosas curas y sucesos que dios nuestro señor a querido obrar por sus manos, en cinquenta años que a que cura, ansi en españa, como en la ysla española, y rreino de tierra firme, [...] En cartagena indiana, año de 1607 y de la hedad del autor 76. [...] .... Salamanca: Universidad de Salamanca, Junta de Castilla y León, 1989 (1607), Libro segundo, discurso 10, p 207; Pedro López de León. Práctica y teórica de las apostemas en general y particular...Zaragoza: Jaime Magallón, 1699, Libro II, Cap II, 10v. Vale le pena señalar que para José de Acosta las guayabas eran las manzanas de América, porque él establecía la analogía de otra manera.

${ }^{10}$ Fernández de Oviedo, Historia general y naturas de las Indias, Tomo II. Lib. VIII. Cap. I.

${ }^{11}$ Archivo General de la Nación de Colombia (de ahora en adelante AGN), Colonia, Visitas de Bolívar, tomo 3, f. 03v.

${ }^{12}$ AGN, Colonia, Visitas de Cauca, tomo 1, ff. 908v y 915r.
} 
fruta assi crudo: assase también, y guisase, y hanzen del diversos potajes, y aun conservas, y en todo dize bien..”(1608, p. 249)

Debido a esta presencia continua a lo largo del año y a la diversidad de consumos posibles, plátanos y bananos se ganaron un espacio importante en la dieta de los diferentes estamentos, ${ }^{13}$ pero, para entender cómo llegó a ser parte de la vida cotidiana, es importante entender cómo se producía y algunos de los circuitos económicos en que entraba. Como lo señaló Fernández de Oviedo para Santo Domingo, también en el Nuevo Reino de Granada, muchos vecinos tenían platanares en sus estancias, porque exigía poco trabajo y siempre había demanda ${ }^{14}$ Desafortunadamente, este tipo de producción dejó poco rastro documental quedan evidencias de su existencia en transacciones de propiedades, pero poco del movimiento de los frutos-; por lo tanto, centraré la mirada sobre los pueblos indígenas, por tres razones: 1) en el Nuevo Reino de Granada, gran parte del abasto agrícola dependía de ellos. 2) Sobre estas unidades se registró información con cierto grado de continuidad, que no solo permite entender la producción, comercialización y consumo y sus proceso. 3) Permite ver cómo la introducción de un nuevo producto vegetal incide en la transformación de prácticas sociales y culturales.

Curiosamente, por medio de la tributación no se impuso la obligación de cultivar y entregar plátanos de manera generalizada. Es más, en la documentación, la tributación de plátanos es marginal y aislada. Se identifica su presencia en no más de diez pueblos indígenas, distribuidos exclusivamente entre las gobernaciones de Cartagena y Antioquia. ${ }^{15}$ ¿Si el plátano fue tan importante en la dieta colonial, por qué desempeñó un papel tan limitado en la tributación indígena, que sostenía la economía de los encomenderos? Se puede apuntar que, por un lado, el trabajo de las plataneras era poco, más allá de desyerbar y cargar los racimos de plátanos de un punto a otro. Incluso en las inmediaciones de Mompox, la obligación no era entregar un cierto número de plátanos al año, sino simplemente limpiar las plataneras de los encomenderos, lo que no solo implicaba cortar las hierbas que afectaran el crecimiento de la plata, sino también talar los árboles o palmas que ya habían producido y, por ende, no producirían más. Sin embargo, este trabajo era relativamente sencillo si se le compara con otro tipo de actividades que se desempeñaban en las encomiendas, como, por ejemplo, el cultivo de cereales, la cría de animales o el trabajo en los trapiches (este estaba prohibido para los indígenas, pero se seguía presentando a los largo de los siglos XVI y XVII). La otra razón es que el precio del plátano era muy bajo comparado con el del trigo o el maíz (por ejemplo, 160 plátanos costaban un peso, en tanto que una hanega de maíz podía valer 2 o 3 pesos). Por lo tanto, a los encomenderos no les resultaba rentable recibir como pago un producto de tan poco valor de mercado, que

\footnotetext{
${ }^{13}$ Una última forma de consumirlo era de forma líquida, pero no he encontrado muchos ejemplos de ellos en el Nuevo Reino de Granada. Además de eso, no hay ninguna referencia a que el plátano se friera.

${ }^{14}$ AGN, Colonia, Visitas de Magdalena, tomo 2, f. 446r.

${ }^{15}$ AGN, Colonia, Visitas de Antioquia, tomo 1, ff. 318v, 327v, 330r y 335v; tomo 2, ff.16v, 55r, 90v y 98r. tomo 3, f. $843 \mathrm{v}$; Visitas de Bolívar, tomo 5, f. 12v; tomo 7, f. 440v; tomo 8, ff. 565v y 880r.
} 
además desviaba la atención de trabajos que demandaban mayor esfuerzo. En las gobernaciones de Cartagena y de Antioquia, donde no había producción triguera y existía una fuerte demanda comercial por los plátanos — para el avituallamiento de viajes marinos y fluviales, o para el sustento de las personas que trabajaban en las minas-(PALLAS, s.f., tomo 2, p. 130) los plátanos eran importantes para ciertos encomenderos, pero no lo suficientemente atractivos para que se impusiera en la mayoría de las tributaciones de los pueblos indígenas de estas dos gobernaciones.

Vale la pena recordar que los encomenderos no eran los únicos que usufructuaban gratuitamente el trabajo de los indígenas. Aunque contraria a la regulación de la época, era una práctica más o menos común que los doctrineros de los pueblos indígenas ocuparan a los menores de 17 años y a las mujeres, personas libres de obligaciones tributarias frente al encomendero y la Corona, en actividades agrícolas o artesanales, para beneficio propio, sin pagarles nada a cambio a los indígenas. Para algunos de ellos era un derecho adquirido de su congrua. A pesar de que es una costumbre extendida en el Nuevo Reino de Granada, solo en dos pueblos, Loba y Guazo — gobernación de Cartagena_, los doctrineros obligaban a los muchachos a que les cultivaran unos platanares. No se contentaban con el trabajo agrícola, sino que además exigían que los muchachos o las mujeres los entregaran deshidratados o pasados al sol. ${ }^{16}$ Ambos doctrineros los enviaban a Zaragoza, la principal ciudad minera de Antioquia y del Nuevo Reino de Granada, en donde no había población indígena para la época, la producción agrícola era sumamente limitada y prácticamente todo el abasto se daba por medio del comercio (GÓMEZ, 2015, p. 147). Los doctrineros no solo buscaban la mejor alternativa económica para sus productos sino que también le daban un valor agregado, por medio de la preparación.

La información sobre la tributación de plátanos es poca y aparece relativamente tarde - 1569 y 1590 son las fechas de las dos apariciones más tempranas-, y solo alcanza mayor presencia a comienzos del XVII. Cuando se mira la documentación sobre autoconsumo, que es mucho más abundante, aparece la misma lógica (muy poco en el siglo XVI, con aumento a fines de ese siglo y una mayor presencia a los largo del siglo XVII). En un principio se puede pensar que es un problema relativo a la fuente. Sin duda puede tener algo que ver. Por ejemplo, no hay visitas de la tierra prácticamente a Santa Marta, que es una gobernación en la que seguramente se introdujo pronto el plátano, en tanto que en la gobernación de Cartagena hubo visitas en 1569, 1589-1590 y 1610-1611. Tal vez el hecho de que las visitas sean tan tardías condiciona la primera aparición documental del plátano en los pueblos indígenas. Sin embargo, no explicaría por qué estaba tan poco extendido en los pueblos de la gobernación antes del siglo XVII. Finalmente, en zonas en las que hubo visitas desde 1555, como la zona central de la audiencia (Santa Fe y Tunja), el plátano comenzó a aparecer en la documentación, como autoconsumo, solo a partir de 1600. Considero que la poca

\footnotetext{
${ }^{16}$ AGN, Colonia, Visitas de Bolívar, tomo 4, ff 530r y 543v; tomo 10, ff. 855r, 862r y 869v. 
presencia del plátano en el siglo XVI, y su mayor presencia a partir de comienzos del XVII, no se debe a un problema documental, sino más bien al lento proceso de apropiación del plátano por parte de las comunidades indígenas.

Las razones para que el plátano haya tenido que esperar hasta comienzos del XVII para extenderse entre los pueblos indígenas no aparecen de manera explícita en la documentación que he consultado. Tal vez la falta de presión española para su cultivo ralentizó su adopción. El problema de esta explicación es que da mucho peso a la dominación hispánica y poco a la capacidad de adaptación indígena a las nuevas condiciones y a los nuevos productos. Sin embargo, vale la pena preguntarse: ¿para qué se iban a apropiar los indígenas de nuevos productos, si los que tenían seguían siendo útiles en términos alimenticios y se producían con cierto grado de facilidad? Se puede pensar que si se demoraron en incorporar el plátano no fue tanto porque no se percataran de sus posibilidades, sino porque sus propios productos no habían perdido para ellos ninguna de sus virtudes y no necesitaban remplazarlos.

Si bien su éxito a partir del siglo XVII es evidente, en las fuentes tampoco se encuentra una explicación que se diera en la época de por qué comenzó a darse en ese momento. ¿Qué cambios se produjeron para que lo integraran en este punto? Hay dos factores que son importantes para entender este proceso, uno demográfico y de esfuerzo en el trabajo, y otro comercial y de consumo.

Del lado demográfico, se puede apuntar que a partir de 1558 comenzaron a presentarse oleadas sucesivas de enfermedades, que se repitieron con cierta periodicidad hasta 1636 . Esto produjo una disminución demográfica indígena acelerada, fenómeno generalizado en las Indias Occidentales. La peculiaridad del Nuevo Reino de Granada es que no se presentó una recuperación de esta población a comienzos del siglo XVII — como sí sucedió en Perú y México-, sino que siguió en un marcado declive (FRANCIS, 2002, p. 62). Como en los pueblos se calculaba la tasa que debían pagar al encomendero sobre el número de indios que estuvieran en edad de tributar, se suponía que era una medida variable, según se contrajera o aumentara la población tributaria. En la realidad, los encomenderos siguieron pidiendo el tributo tal como se había fijado por los visitadores, sin tener en cuenta que había menos tributarios, porque había muerto la gran mayoría y porque algunos habían abandonado el pueblo. De esta manera, progresivamente aumentó el trabajo de los tributarios, porque debían pagar su parte y la de los ausentes. A causa de la mayor presión tributaria, muchos pueblos tenían menos tiempo para hacer sus propias rozas, razón por la cual ganaron presencia en la dieta y en la producción productos que generaran menos esfuerzo. Por ejemplo, el plátano y las gallinas. A diferencia del maíz, que exigía un trabajo intensivo de temporadas y luego uno de protección y mantenimiento hasta que se recogiera, el plátano demandaba poco trabajo a lo largo del año, y tenía la ventaja de proveer comida de manera más constante que otros cultivos. Un ejemplo de esta forma de entrar el plátano en la dieta de los indígenas lo podemos encontrar entre los indios que trabajaban en las 
minas cerca de Anserma, a los que el encomendero no cumplía con su obligación de proveerlos de alimentos (carne y maíz, fundamentalmente), y por esto debían ocuparse, en la mañana y en la tarde, antes y después de su jornada minera, de sus platanares y yucales. ${ }^{17}$ Hacer esto con el maíz era imposible, pero con platanares y yucales era viable dedicar un poco tiempo al día para garantizar un sustento diario. Esto no implicó necesariamente que el maíz perdiera presencia en las comunidades, sino que se abrieron espacios para el consumo de productos nuevos, que se articulaban bien con sus posibilidades productivas y que se complementaran con los ciclos agrícolas que ya manejaban.

Por el lado comercial, se puede apuntar que la implantación de un modelo de vida cristiano obligó a los indígenas a consumir cada vez más productos o servicios que se conseguían principalmente por la compra, con dinero o por medio de trueque. Entre otros, estaban las bulas de cruzada, prendas de vestir, herramientas de trabajo y una lista más o menos larga de elementos. La forma para conseguir el oro, el dinero o los productos con los cuales intercambiarlos se dividían en varios tipos: alquiler (concierto) de la mano de obra, trabajo artesanal y venta de productos agropecuarios. En este último aspecto, el plátano, junto con las gallinas, el maíz y en ocasiones el trigo y papas desempeñaban un papel importante (SALDARRIAGA, 2015, pp. 57-84). El plátano ocupaba un renglón inferior a estos dos, por lo menos con respecto a estima. Sin embargo, ocupaba un renglón muy importante con respecto a producción, porque solo algunos pueblos de tierras frías tenían para vender trigo, en cambio muchos de tierra templada y cálida tenían plátanos para comerciar. Incluso los pueblos que estaban asentados en tierra fría, pero poseían tierras en diferentes pisos térmicos, tenían excedentes de plátanos, como los indios de Fontibón, Tibito y Pacho. ${ }^{18} \mathrm{O}$ bien, algunos indios muiscas, de tierra fría, iban a tierra de los panches a comprar plátanos para llevarlos después a diferentes mercados, donde sus compradores eran fundamentalmente españoles e indios que habitaban en las ciudades. ${ }^{19}$ No se afirma que el plátano fuera el eje del comercio de los indígenas con la sociedad colonial, sino que este comercio incentivó el cultivo de plátano porque le daba salida a un producto de poco esfuerzo, que no restaba tiempo a otros cultivos, que tenía la demanda asegurada y no competía, por lo menos en el mercado, con los encomenderos, porque muy pocos de ellos tenían venta de plátanos. Aunque no tenía un precio muy alto, su gran demanda, aseguraba un ingreso permanente para las comunidades que se dedicaban a venderlo.

Esta conjunción de factores hizo que, en el siglo XVII, el plátano se integrara al mundo indígena como una de las frutas de tierra caliente. Si bien hubo que esperar cerca de 80 años en el Nuevo Reino de Granada, una vez arraigó entre los pueblos de indios, se volvió parte del paisaje y llegó a convertirse en una fruta endémica, prácticamente aborigen.

\footnotetext{
${ }^{17}$ AGN, Colonia, Visitas de Cauca, tomo 2, f. 318v.

${ }^{18}$ AGN, Colonia, Visitas de Cundinamarca, tomo 12, ff. 345v, 1005v, 1007v, 1008r.

${ }^{19}$ AGN, Colonia, Visitas de Cundinamarca, tomo 3 f. $1018 \mathrm{r}$.
} 
Con esta fruta es posible ver otro rostro de eso que con Crosby se ha llamado imperialismo ecológico. Porque a diferencia de lo que apuntó este insigne autor, en este caso no se trató de la expansión biológica de Europa, sino de los europeos como vector de expansión de un producto asiático que ocupaba un lugar poco importante en sus consideraciones alimenticias.

Con respecto a la forma en que se adaptan los indígenas, se ven también otros engranajes del imperio y su increíble capacidad de transformación. Acorde con las categorías que utilizó ya hace muchos años

Wachtel, se podría apuntar que el proceso de adopción del plátano por parte de los indígenas correspondería a una forma de aculturación espontánea, es decir, un cambio cultural que los españoles no buscaron voluntariamente, sino que se presentó por la porosidad de los vasos comunicantes entre los grupos (1085, p. 141). En el Nuevo Reino de Granada es claro que los españoles no hicieron grandes esfuerzos para que los indígenas cultivaran el plátano, pero la presencia española en el territorio desencadenó un conjunto de factores que produjeron esta adopción: enfermedad, disminución demográfica, sobreexplotación laboral, demandas de consumo cristiano y mercados monetizados que exigían ciertos productos. Por último, si bien todos estos procesos estructurales se presentaron, esta de aculturación se dio porque, en un momento dado, los indígenas tuvieron la voluntad de abrazar este producto y apropiárselo con tal intensidad y convicción que lograron que olvidáramos que era una comida traída del otro extremo del mundo.

\section{FUENTES IMPRESAS}

ACOSTA, José de. Historia Natural y moral de las India. Madrid: Casa de Alonso Martín, 1608, p. 535.

CARLETTI, Francesco. Ragionamenti del mio viaggio intorno al mondo. Torino: Einaudi, 1989, p. 237.

Razonamientos de mi viaje alrededor del mundo (1594-1606). Estudio preliminar, traducción y notas de Francisca Perujo. México: Instituto de Investigaciones Bibliográficas, UNAM, 1976, p. 281.

"Carta del licenciado Xoan de Vadillo a su magestad quenta de su visita a la gobernación de Cartagena. Cartagena, octubre 15 de 1537", en Colección de documentos inéditos, relativos al descubrimiento, conquista y colonización de las posesiones españolas en América y Oceanía sacados en su mayor parte del real Archivo de indias. Madrid: Imprenta Española, 1864-1884, Tomo XLI, p. 397-420.

DURANTE, Castore. Il tesoro della sanità, di Castor Durante da Gualdo, medico, \& Cittàdino Romano. Nel quale s ínsegna il modo di conservar la sanità, \& prolongar la vita, \& si tratta della natura décibi, \& di Rimedi de nocumenti loro. Venetia: Gio Battista Cestaro, 1646, p. 320.

FERNÁNDEZ DE OVIEDO, Gonzalo. Historia General y Natural de las Indias Islas y Tierra Firme del mar Océano, 10 vols. Asunción: Guaranía, 1944.

FRAGOSO, Juan. Cirugia universal, ahora nuevamente añadida, con todas las dificultades, y questiones, pertenecientes a las materias de que se trata. Madrid, Viuda de Alonso Martín, 1627, p. 938. 
LABAT, Jean-Baptiste. Viajes a las islas de la América. La Habana: Casa de las América, 1979, p. 324.

LÓPEZ DE LEÓN, Pedro. Práctica y teórica de las apostemas en general y particular...Zaragoza: Jaime Magallón, 1699, f. 370.

LÓPEZ MEDEL, Tomás. De los tres elementos. Tratado sobre la naturaleza y el hombre del Nuevo Mundo, edición de Berta Ares Queija, Alianza, Madrid, 1990, p. 299.

MÉNDEZ NIETO, Juan. Discursos medicinales compuestos por el licenciado Juan Mendez Nieto, que tratan de las maravillosas curas y sucesos que dios nuestro señor a querido obrar por sus manos, en cinquenta años que a que cura, ansi en españa, como en la ysla española, y rreino de tierra firme, [...] En cartagena indiana, año de 1607 y de la hedad del autor 76. [...] Salamanca: Universidad de Salamanca, Junta de Castilla y León, 1989 (1607), p. 558.

PALLAS, Gerónimo. Misión a las Indias con Advertencias para los Religiosos de Europa, que la hubieran de emprender, como primero se verá en la historia de un viaje y después en discurso. tomo 2, p. 27 f. 130. Versión disponible en http://www.archivodelafrontera.com/wp-content/uploads/2011/08/GFUENTES-01PALLAS_02_libro1.pdf. Consultado en el 15 de febrero de 2007.

\section{BIBLIOGRAFÍA}

CASTILLERO CALVO, Alfredo. Sociedad, economía y cultura material. Historia urbana de Panamá la Vieja. Panamá: Patronato de Panamá Viejo, 2006, p.1062

EARLE, Rebecca. The Body of the Conquistador. Food, Race and the Colonial Experience in Spanish America, 1492-1700. New York: Cambridge University Press, 2012, p. 254.

FRANCIS, Michael J. "Población, enfermedad y cambio demográfico, 1537-1636. Demografía histórica de Tunja: una mirada crítica", Fronteras de la Historia, Bogotá, n.7, p. 13-76, 2002.

GÓMEZ, Mauricio. Del chontal al ladino. Hispanización de los indios de Antioquia según la visita de Francisco de Herrera Campuzano, 1614-1616. Medellín: FCSH, 2015, p. 190.

GRIECO, Allen J. "Alimentation et classes sociales à la fin du Moyen Age et à la Renaissance". In: FLANDRIN, Jean-Louis y MONTANARI (eds), Massimo, Histoire de l'alimentation. Paris: Fayard, 1996, cap. XXVII, p. 479-490.

pp. 131-149, 1991.

"The Social Politics of pre-Linnean Botanical Classification", I Tatti Studies, Florencia, n.4,

MONTANARI, Massimo. La comida como cultura. Gijón: Trea, 2006, p.126.

SALDARRIAGA, Gregorio. "El trigo en el Nuevo Reino de Granada, siglos XVI y XVII: imposición y establecimiento de un eje alimentario entre las poblaciones indígenas". In: Diana Bonnett Vélez (editora académica), Una obra para la Historia: Homenaje a Germán Colmenares, Bogotá, Universidad del Rosario, cap. IV, p. 57-84. 
Musas en el paraíso:

Apropriaciones del plátano por parte de españoles e indígenas. Nuevo Reino de granada, siglos XVI y XVII.

Gregorio SALDARRIAGA

"Comer y ser. La alimentación como política de la diferenciación social en la América española, siglos XVI y XVII” Varia Historia, Belo Horizonte, 32.58, p. 53-77. 2016

WACHTEL, Nathan. "La aculturación", LE GOFF, Jacques y NORA, Pierre (eds), Hacer la Historia, t. 1, Nuevos Problemas. Barcelona: Laia, 1985, pp. 135.

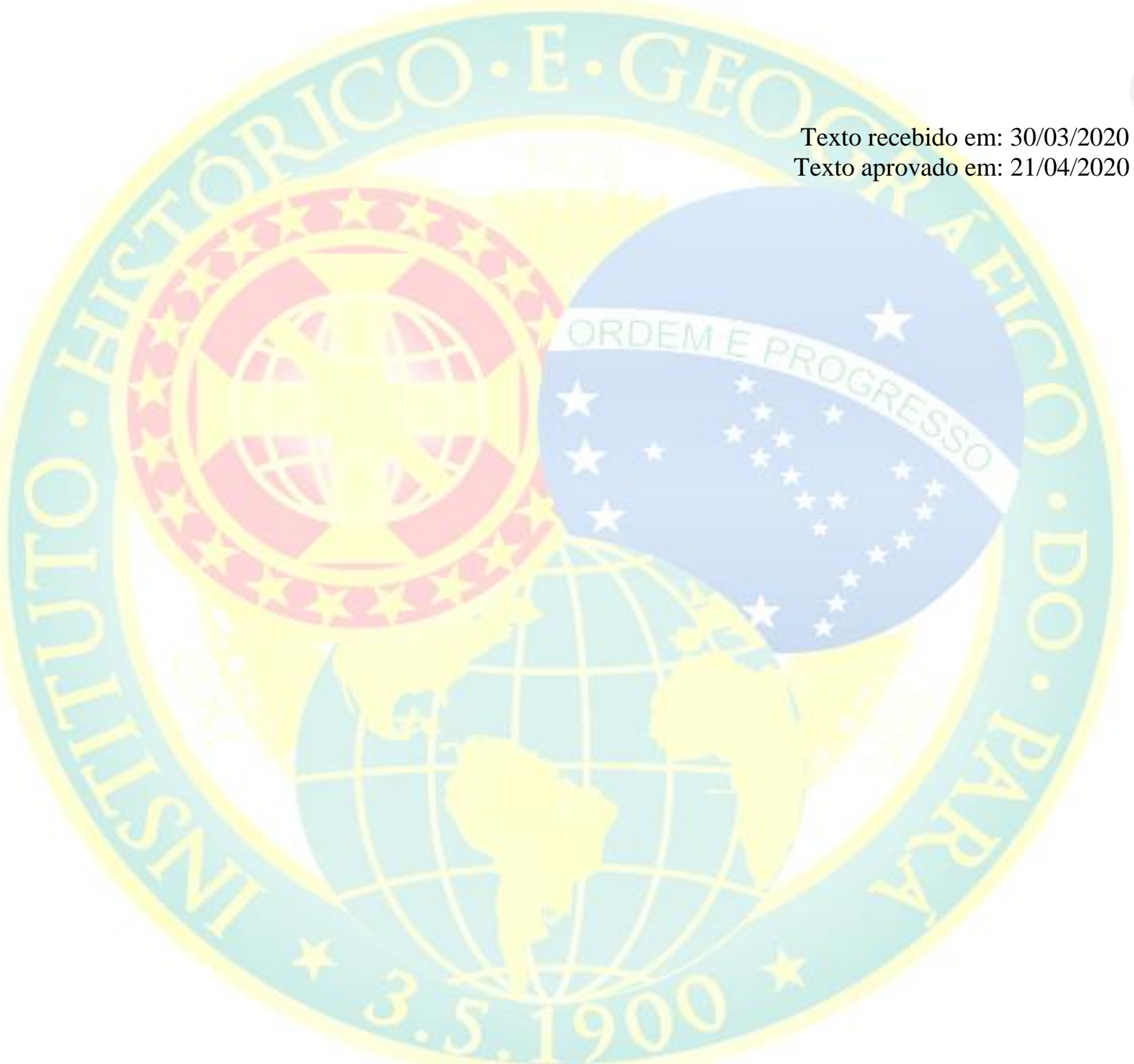

